\title{
Accuracy of fine needle aspiration cytology in diagnosis of thyroid swelling.
}

\author{
Hirachand $\mathrm{S}^{1}$, Maharjan $\mathrm{M}^{2}$, Lakhey $\mathrm{M}^{1}$, Thapa $\mathrm{R}^{1}$, Kafle $\mathrm{S}^{1}$ \\ ${ }^{I}$ Department of Pathology, Kathmandu Medical College and Teaching Hospital, Kathmandu, Nepal \\ ${ }^{2}$ Department of ENT, Kathmandu Medical College and Teaching Hospital, Kathmandu, Nepal
}

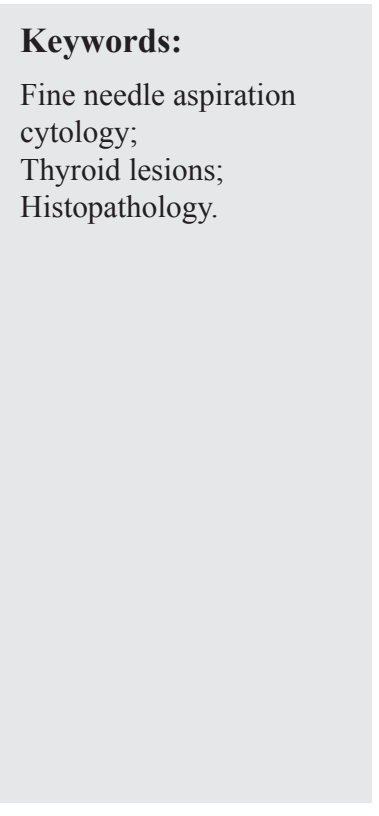

\begin{abstract}
Background: Fine needle aspiration cytology has been shown to be simple, safe, cost effective and quick to perform procedure with excellent patient compliance. It is a well established technique for preoperative investigation of thyroid gland swellings with high sensitivity, specificity and accuracy. The aim of this study was to determine the accuracy of fine needle aspiration cytology of thyroid swellings performed at our institution.
\end{abstract}

Materials and Methods: This study was carried out at Kathmandu Medical College and Teaching hospital, department of Pathology over a period of 3 years (January 2010 to December 2012). Two hundred and seventy three patients of all age groups and both sexes who underwent fine needle aspiration cytology for thyroid swelling were evaluated. Out of 273 patients, histopathological diagnosis was available in 45 patients.

Results: Fine needle aspiration cytology result revealed 245 cases $(89.7 \%)$ as non-neoplastic, 21 cases $(7.7 \%)$ as neoplastic and 7 cases $(2.6 \%)$ inadequate due to lack of cellularity. The commonest lesion in the thyroid gland was colloid goiter. Among the malignant neoplasms the commonest was papillary carcinoma. Out of 273 patients, histopathological diagnosis was available in 45 patients. Statistical analysis of our data shows the diagnostic accuracy of fine needle aspiration cytology to be $95.7 \%$. Fine needle aspiration cytology showed a sensitivity of $96.4 \%$ and a specificity of $94.4 \%$.

Conclusion: Fine needle aspiration cytology is a well established technique for pre operative investigation of thyroid gland swellings with high sensitivity, specificity and accuracy.

\section{INTRODUCTION}

Enlargement of thyroid gland is a common occurrence in most parts of the world especially in the iodine deficient goiter belt areas, where the prevalence may be as high as $40 \%{ }^{1}$ The development of goiter is a concern to both the patient and the clinician because of the fear that the swelling may be malignant. Most goiters are benign and even in solitary nodules selected for surgery or clinical grounds malignancy is found in only around $10 \%{ }^{2}$

\author{
Correspondence: \\ Dr. Suspana Hirachand, MD \\ Department of Pathology, Kathmandu Medical College and Teaching \\ Hospital, Kathmandu, Nepal \\ Email: suspi1974@hotmail.com
}

Thyroid scintigraphy, ultrasonography and biochemical tests provide little help in resolving the diagnostic problem. Fine needle aspiration cytology (FNAC) has been used for preoperative diagnosis for more than half a century. This method has gained worldwide acceptance during the last two decades and has been recommended as the first choice for the evaluation of thyroid pathology.-5 Fine needle aspiration cytology has been shown to be simple, safe, cost effective and quick to perform procedure with excellent patient compliance.

The aim of this study was to determine the accuracy of fine needle aspiration cytology of thyroid swellings performed at our institution. 


\section{MATERIALS AND METHODS}

This study was carried out at Kathmandu Medical College and Teaching hospital, department of Pathology over a period of 3 years (January 2010 to December 2012). Two hundred and seventy three patients of all age groups and both sexes who underwent FNAC for thyroid swelling were evaluated. Out of 273 patients, histopathological diagnosis was available in 45 patients.

Fine needle aspiration cytology was performed without local anesthesia with the help of the non-aspiration technique, using 23-24 gauge needles. Multiple passes were made through the centre and the periphery of the swellings. Both air-dried and alcohol fixed smears were made from the aspirated material, stained with May-Grunwald Giemsa (MGG) and Papanicolaou (PAP) stains. Histopathology slides were stained with Haematoxylin and Eosin (H\&E) were reviewed.

Fine needle aspiration cytology results were classified into the following three groups:

a) inadequate (no diagnosis was made because of inadequate cellular material)

b) non-neoplastic (including multinodular goiter, colloid goiter, thyroiditis)

c) neoplastic (benign- Hurthle cell neoplasm, follicular neoplasm, andmalignant-papillarycarcinoma, medullary carcinoma, anaplastic carcinoma).

Histology specimens were classified as non-neoplastic and neoplastic. Preoperative FNAC results were than compared with the definitive histological diagnosis. The sensitivity, specificity and accuracy of FNAC in diagnosing thyroid malignancy were calculated.

\section{RESULTS}

A total 273 patients with thyroid swelling were studied which includes 243 female and 30 male with F: M ratio of 12.3:1. Age of the patients ranged from 15 to 60 years.

The major presenting symptom in all patients was diffuse or nodular swelling of the thyroid. Other symptoms were less frequent: pain in the thyroid region in 13 patients, hoarseness of voice in 11 patients and dysphagia in 7 patients.

Thyroid function tests were performed in 207 patients (75.8\%) out of which $110(53.1 \%)$ were found to be euthyroid, 60 hyperthyroid (29\%) and 37 hypothyroid (17.9\%). Hyperthyroid occurred in 25 patients with solitary or multiple nodules, 19 patients with diffuse swelling and 16 patients with thyroiditis.

Fine needle aspiration cytology result revealed 245 cases
Table 1: FNAC results of 273 patients

\begin{tabular}{|c|c|}
\hline FNAC diagnosis & Number of patients (\%) \\
\hline $\begin{array}{l}\text { Non- neoplastic } \\
\text { • Colloid goiter } \\
\text { - Adenomatoid goiter } \\
\text { - Thyroiditis }\end{array}$ & $\begin{array}{l}\mathbf{n}=\mathbf{2 4 5} \\
198(72.53 \%) \\
7(2.56 \%) \\
40(14.65 \%)\end{array}$ \\
\hline $\begin{array}{l}\text { Neoplastic } \\
\text { Benign }\end{array}$ & $\mathbf{n}=\mathbf{2 1}$ \\
\hline $\begin{array}{l}\text { - Hurthle cell neoplasm } \\
\text { - Follicular neoplasm }\end{array}$ & $\begin{array}{l}2(0.73 \%) \\
3(1.10 \%)\end{array}$ \\
\hline $\begin{array}{l}\text { Malignant } \\
\text { - Papillary carcinoma } \\
\text { - Follicular carcinoma } \\
\text { - Medullary carcinoma } \\
\text { - Anaplastic carcinoma } \\
\text { Inadequate } \\
\end{array}$ & $\begin{array}{l}13(4.76 \%) \\
1(0.37 \%) \\
1(0.37 \%) \\
1(0.37 \%) \\
7(2.56 \%) \\
\end{array}$ \\
\hline Total & 273 \\
\hline
\end{tabular}

(89.7\%) as non-neoplastic, 21 cases (7.7\%) as neoplastic and 7 cases $(2.6 \%)$ inadequate due to lack of cellularity (Table 1).

The most common lesion in the thyroid gland was colloid goiter. Among the malignant neoplasms the commonest was papillary carcinoma (fig. 1\&2).

Out of 273 patients, histopathological diagnosis was available in 45 patients. Comparison between cytopathological and histopathological diagnosis is shown in Table 2.

Statistical analysis of our data shows the diagnostic accuracy of FNAC to be $95.7 \%$. Fine needle aspiration cytology showed a sensitivity of $96.4 \%$ and a specificity of $94.4 \%$.

\section{DISCUSSION}

Fine needle aspiration cytology is regarded as the gold standard initial investigation in the diagnosis of thyroid swellings. The technique is safe, simple and quick with low complication rates. Several other tests such as high resolution ultrasonography, radioisotope scanning and FNA biopsy have been used for evaluation of thyroid swellings before proceeding to thyroid surgery. Studies have demonstrated that among all these diagnostic modalities, FNAC is the most accurate and cost effective screening test for rapid diagnosis of thyroid swellings. ${ }^{6-8}$

Fine needle aspiration has been shown to have similar or even higher sensitivity and accuracy levels than frozen section examination. ${ }^{9-11}$

The sensitivity of thyroid FNAC ranges from $52 \%$ to $93.5 \%$, specificity from $75 \%$ to $98.5 \%$ and accuracy from $79.1 \%$ to $87 \%{ }^{12-15}$ as shown in Table 3.

In our study, the sensitivity, specificity and accuracy were 


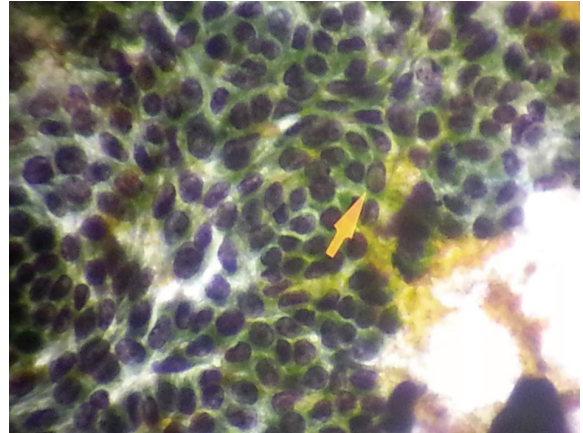

Figure 1: Papillary carcinoma showing intranuclear cytoplasmic pseudoinclusion(Pap stain, X40).

$96.4 \%, 94.4 \%$ and $95.7 \%$ respectively.

The inadequacy rate in this study was $2.6 \%$. Previous studies have shown the percentage of inadequate material ranged from $9 \%$ to $31 \%$. The most important factors include experience of the aspirator and the criteria used to define a satisfactory sample.

The cyto-histopathological concordance rate in our study in colloid goiters turned out to be $96.4 \%$ (27/28 cases). Various studies have shown concordance between cytology and histology to vary between $80 \%$ and $100 \%$. $^{16-18}$

A single false negative case (2.2\%) diagnosed cytologically as a colloid goiter with cystic change, was eventually diagnosed as a follicular adenoma on histopathological examination. This can be explained on the basis of the sampling areas of cystic change rather than cellular areas. Occurrence of cystic change in thyroid lesions is a common and well-known diagnostic pitfall in cytology. Different

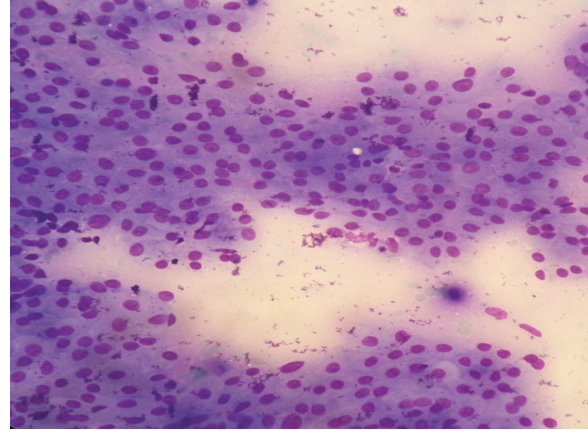

Figure 2: Hurthle cell neoplasm (Giemsa stain, X40). studies showed false negative results ranging from $1.5 \%$ to $11.5 \% .^{8,19,20}$

In our study one case (2.2\%) was diagnosed as a follicular neoplasm on FNAC, which on histopathology turned out to be colloid goiter. A sampled focal are of high cellularity of the lesion could have lead to misdiagnosis on FNAC. This is within the range of other studies, which have showed false positive rates ranging from 0 to $8 \%{ }^{8,19,20}$

\section{CONCLUSION}

Fine needle aspiration cytology is a well established technique for pre operative investigation of thyroid gland swellings with high sensitivity, specificity and accuracy. This technique is almost non-invasive, cost effective and free of complications in expert hands and an efficient method of differentiating benign and malignant lesions, thereby reducing unnecessary surgeries.

Table 2: Correlation of cytological and histological diagnosis $(n=45)$

\begin{tabular}{|c|c|c|c|c|c|}
\hline Cytological diagnosis & & & Histological diagnosis & & \\
\hline Colloid goiter & Colloid goiter & Follicular adenoma & Hurthle cell adenoma & Papillary Ca & Anaplastic $\mathrm{Ca}$ \\
\hline Follicular neoplasm & 5 & 4 & 4 & 5 & 4 \\
\hline Hurthle cell neoplasm & 10 & 10 & 9 & 10 & 9 \\
\hline Papillary carcinoma & 3 & 0 & 0 & 3 & 3 \\
\hline Anaplastic carcinoma & 1 & 0 & 1 & 1 & 1 \\
\hline Total & 28 & 3 & 1 & 12 & 1 \\
\hline
\end{tabular}

Table 3: Distribution of $B$ and $T$ cell ALL cases according to immunophenotype

$\begin{array}{rccccc} & \text { This study 2013 } & \begin{array}{c}\text { Bouvet M et.al12 } \\ \mathbf{1 9 9 2}\end{array} & \begin{array}{c}\text { Kessler A } \\ \text { et al13 2005 }\end{array} & \begin{array}{c}\text { Gupta M et al14 } \\ \mathbf{2 0 1 0}\end{array} & \begin{array}{c}\text { Mundasal B et all15 } \\ \mathbf{2 0 0 6}\end{array} \\ \text { Sensitivity } & 96.4 \% & 93.5 \% & 79 \% & 80 \% & 52 \% \\ \text { Specificity } & 94.4 \% & 75 \% & 98.5 \% & 86.6 \% & 86.6 \% \\ \text { Accuracy } & 95.7 \% & 79.6 \% & 87 \% & 84 \% & 79.1 \%\end{array}$


A benign FNAC diagnosis should be viewed with caution as false negative results do occur and these patients should be followed up. Any clinical suspicion of malignancy even in the presence of a benign FNAC diagnosis may require surgical intervention.

\section{REFERENCES}

1. Agarwal S. Diagnostic accuracy and role of fine needle aspiration cytology in management of thyroid nodules. J Surg Oncol $1995 ; 58: 168-72$.

2. Rojeski MT, Gharib H. Nodular thyroid disease. Evaluation and management. New Eng J Med 1985;313:428-36.

3. Bugis SP, Young JEM, Archibald SD et al. Diagnostic accuracy of fine needle aspiration biopsy versus frozen section in solitary thyroid nodules. Am J Surg 1986;152:411-6.

4. Lennquist $\mathrm{S}$. The thyroid nodule, diagnosis and surgical treatment. Surg Clin North Am 1987;67:213-2.

5. Silverman JF, West RL, Larkin EW. The role of fine needle aspiration biopsy in the rapid diagnosis and management of thyroid neoplasm. Cancer 1986;57:1164-70.

6. Campbell JP, Pillsbury HC. Management of thyroid nodule. Head Neck 1989;11:414-25.

7. Reeve D, Debridge L, Slaon D, Crummer P. The impact of fine needle biopsy on surgery for single thyroid nodule. Med J Aust 1986;145:308-11.

8. Caruso P, Muzzaferri EL. Fine needle aspiration biopsy in the management of thyroid nodules. Endocrinology 1991;1:194-202.

9. Baloch ZW, Sack MJ, Yu GH, LiivolsiVa, Gupta PK. Fine needle aspiration of thyroid: an institutional experience. Thyroid 1998;8:5659.

10. Boyd CA, Eamhardt RC, Dunn JT, Frierson HF, Hanks JB. Preoperative evaluation and predictive value of fine needle aspiration and frozen section of thyroid nodule. J Am Coll Surg 1998;187:494502.
11. Layfield LJ, Reichman A, Bottles K, Giulians A. Clinical determinants for the management of thyroid nodules by fine needle aspiration cytology. Arch Otolary Head Neck Surg 1992;118:717-21.

12. Bouvet M, Feldman JI, Gill GN. Surgical management of the thyroid nodule: Patient selection based on the results of fine needle aspiration cytology. Laryngoscope 1992;102:1353-6.

13. Kessle A, Gavriel H, Zahav S. Accuracy and consistency of fine needle aspiration biopsy in the diagnosis and management of solitary thyroid nodules. Israel Medical Association Journal 2005;7:371-3.

14. Gupta M, Gupta S, Gupta VB. Correlation of fine needle aspiration cytology with histopathology in the diagnosis of solitary thyroid nodule. Journal of thyroid research 2010; Article ID 379051, 5 pages,2010. doi:10.4061/2010/379051.

15. Mundasal B, Mcallister I, Causon J, Pyper PC. Accuracy of fine needle aspiration cytology in diagnosis of thyroid swelling. The internet Journal of Endocrinology 2006;2:1-4.

16. Das DK, Khanna CM, Tripathi RP, Pant CS. Solitary nodular goiter: review of cytomorphological features in 441 cases. Acta Cytol 1994;43:563-74.

17. Kumori T, Shinya H, Satomi T, Abe M, Kawaguchi S. management of nodular goiter and their operative indications. Surg Today 2003;30:722-6.

18. Schurner LB, Widstrom AK. Fine needle aspiration cytology of the thyroid gland. A cytohistological comparison in cases of goiter. Ann Otol Rhinol Laryngol 1978;87:224-7.

19. Gharib H, Goellner JR. Fine needle aspiration biopsy of the thyroid: An appraisal. Ann Internet Med 1993;118:282-9.

20. Guidelines of the Papnicoloau Society of Cytopathology for the examination of fine needle aspiration specimens from thyroid nodules. Mod Pathol 1996;9:710-5. 